\title{
Is 'five-a-day' an effective way of increasing fruit and vegetable intakes?
}

\author{
PAL Ashfield-Watt ${ }^{1}$, AA Welch ${ }^{1}$, NE Day ${ }^{1}$ and SA Bingham ${ }^{2, *}$ \\ ${ }^{1} E P I C$, University of Cambridge, Institute of Public Health and Strangeways Research Laboratories, Worts Causeway, \\ Cambridge CB1 8RN, UK: ${ }^{2}$ Medical Research Council, Dunn Nutrition Unit, Wellcome Trust MRC Building, \\ Hills Road, Cambridge CB2 2XY, UK
}

Submitted 9 April 2003: Accepted 30 July 2003

\begin{abstract}
Objectives: To assess whether the amount of fruits and vegetables consumed depends on the serving size or on how often fruits and vegetables are eaten.

Design: Estimation of the weight of serving sizes and the number of fruits and vegetables eaten daily, using a validated food diary method.

Setting: Free-living men and women participating in the Norfolk arm of the European Prospective Investigation into Cancer and Nutrition (EPIC).

Subjects: Two hundred and sixty-nine men and women sampled from EPIC-Norfolk to participate in a study of simple methods of assessing fruit and vegetable intakes. Results: The average portion of all fruits and vegetables measured was $87 \mathrm{~g}$, close to the standard portion size of $80 \mathrm{~g}$ used as the basis of '5-a-day' recommendations. There was a wide variation; the average portion size for baked beans was $147 \mathrm{~g}$ while for lettuce it was $26 \mathrm{~g}$. The 20th and 80th percentiles also showed a large range, e.g. $39-72 \mathrm{~g}$ for carrots and $60-150 \mathrm{~g}$ for strawberries. Women ate more fruit than did men but fewer vegetables, so the total amount of fruit and vegetables eaten by men and women was the same. High consumers of fruits and vegetables $\left(\geq 400 \mathrm{~g} \mathrm{day}^{-1}\right)$ ate them $\sim 5$ times a day whilst low consumers $\left(<400 \mathrm{~g} \mathrm{day}^{-1}\right)$ ate them less often $(\sim 3$ servings per day, $P<0.01$ ). Portion size differed little between high and low consumers.

Conclusions: Frequency of intake is more important than portion size when distinguishing between high and low consumption of fruits and vegetables. Therefore, to increase intakes, low consumers should eat fruits and vegetables more often. This endorses the '5-a-day' healthy eating message.
\end{abstract}

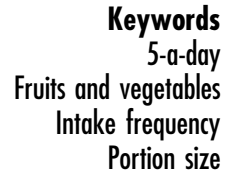

5-ards

Portion size
Despite evidence that diets poor in fruit and vegetables are associated with increased risk of cardiovascular disease (CVD) and certain cancers, fruit and vegetable intakes in the UK remain below recommended levels and amongst the lowest in Europe. On average, $314 \mathrm{~g}$ of fruit and vegetables are consumed per person daily in the $\mathrm{UK}^{1}$ compared with over $450 \mathrm{~g} \mathrm{day}^{-1}$ in Southern European countries $^{2,3}$. The World Health Organization's target of $400 \mathrm{~g} \mathrm{day}^{-1}$ of fruits and vegetables is based on intakes in countries with low premature mortality from CVD and cancer ${ }^{4}$. This recommendation generally translates to five portions of mixed fruit and vegetables a day (excluding potatoes and including only one portion of fruit juice) and forms the basis of the Department of Health's and other health agencies' '5-a-day' initiatives.

The reason for the current low level of consumption in Britain is unknown. Is it because fruit and vegetable intake is infrequent or because serving sizes are too small? Current recommendations for '5-a-day' are based upon an average portion weighing $80 \mathrm{~g}$, but there are few published data available from population studies to support this. We have therefore investigated the weights of fruits and vegetables consumed by free-living individuals in a sample of UK adults.

\section{Subjects and methods}

The European Prospective Investigation into Cancer and Nutrition (EPIC) is an international study of the relationship between dietary factors, nutrition and disease in nine European countries. The UK component of this study (EPIC-Norfolk) comprises 25000 men and women aged 40-75 years who were first surveyed in 1993-1997. Detailed dietary data were collected from these subjects using an extensively validated 7-day food diary that has been shown to provide good estimates of total fruit and vegetable intakes when compared with the weighed dietary intake method ${ }^{5}$. 
Instruction was given to aid completion of the food diary, which involved a detailed description of the food items consumed, cooking methods used and amounts eaten using household measures (tablespoons, bowls, glasses, units, slices, packets) or 17 sets of colour photographs illustrating small, medium and large portions of individual foods.

Diaries were processed using software that converts descriptions of foods eaten into portion weights. This software, DINER (Data Into Nutrients for Epidemiological Research), was developed specifically for assessing nutrient intakes in the EPIC-Norfolk study ${ }^{6}$ and includes a suite of programs and databases that map reported foods to food-specific portion sizes and applies conversion factors for food density, cooking weight loss/gain and inedible waste. Output weights for each food, therefore, relate to edible portion only. Portion weight data used in DINER were derived from food product manufacturers, from published sources ${ }^{7}$ and by direct measurement of foods. Data derived from EPIC-Norfolk dietary validation studies were used to verify published portion weights for individual food units and were substituted if published values were inappropriate or out of date. Weights for foods not consumed as individual units, e.g. chopped vegetables, were also derived from unpublished EPIC data.

Individuals for this study were chosen by a systematic 1-in-8 sampling from a larger database of 3370 subjects whose food diaries had been coded by April 2000. Three hundred and seventy-eight individuals who had not moved were approached, and then again 1 year later, to take part in a study to test simpler methods of obtaining information on fruit and vegetable intakes. Data from the food diaries of the 269 subjects who responded to both these approaches were included in this study.

The group comprised 116 men and 153 women with a mean age of 69 (standard deviation (SD) 8) and 68 (SD 9) years, respectively. These 269 subjects recorded 7868 servings of fruit (including fruit juice) and vegetables (excluding potatoes) over a mean of 7 days of records. Data on general vegetables and fruits, vegetables dishes, vegetable soups, beans and lentils (dried/canned) were included, and for composite foods (e.g. vegetable dishes and soups) the percentage weight of vegetables per portion was calculated using standard recipe data. The decimal fraction was then used as a conversion factor and applied to obtain the weight of vegetables included in each dish.

Foods eaten in very small amounts that could not be considered to constitute a portion, e.g. fruit and vegetables used as condiments such as lemon juice and tomato purée, were excluded. Coleslaw and other salad-type foods eaten in relatively small quantities and containing $>40 \%$ mayonnaise were also excluded, as were foods eaten by only one subject. To be representative of the wide variation in serving sizes, all occurrences of each of the remaining foods in the dataset were considered to be a serving of that food. No outliers were removed from the dataset.

\section{Statistical analysis}

Average serving sizes for commonly consumed fruits and vegetables were calculated as the total weight in grams of all occurrences of each food reported in the food diaries, divided by the number of occurrences of that food. Summary variables were calculated for all fruits (total fruits), all vegetables (total vegetables) and all fruits and vegetables (combined fruit and vegetables) for each subject. For each summary variable, total intakes were calculated as the total weight consumed, divided by the number of days on which each subject kept records $\left(\mathrm{g} \mathrm{day}^{-1}\right)$. Intake frequencies (servings day ${ }^{-1}$ ) were calculated as the number of occurrences divided by the number of diary days for individual subjects. Average serving size (g serving ${ }^{-1}$ ) was calculated as the weight $(\mathrm{g})$ divided by the number of servings consumed by each subject. Data on subjects who consumed either no fruits or no vegetables were excluded from the calculation of average serving size of that food. The summary variables described above were positively skewed, but approximated a Gaussian distribution following either logarithmic or square-root transformation. Unless otherwise stated, these data are presented in the tables and text as unadjusted geometric means and 95\% confidence intervals (95\% CIs). The effects of age, sex and intake level on the variables described above were assessed using linear regression analysis. Age was stratified into quintiles and entered into each model as a categorical variable. The relationships observed were not materially altered by adjusting for body mass index or for smoking habit (owing to the small number of current smokers).

\section{Results}

\section{Total fruit and vegetable intakes}

Men and women had different patterns of fruit and vegetable intake. Table 1 shows that men tended to eat more vegetables than did women, but women ate considerably more fruit than did men and consequently more total fruit and vegetables overall. However, intakes were influenced by age, with subjects in the lowest quintile of age (Q1, $\leq 60$ years) having the highest intakes and subjects in the highest quintile of age (Q5, > 76 years) having the lowest intakes (Q1 vs. Q5: combined fruits and vegetables, $P<0.01$; fruits, $P<0.05$; vegetables, $P<0.05)$. After adjustment for differences in age, it was observed that women ate significantly more fruit than did men $(P<0.01)$ and men ate more vegetables than did women $(P<0.05)$, but total intakes of fruit and vegetables combined were not different between sexes $(P=0.22)$. Women consumed a greater proportion of fruits than of 
Table 1 Fruit and vegetable intakes for men and women

\begin{tabular}{|c|c|c|c|c|c|c|c|c|c|}
\hline & \multicolumn{4}{|c|}{ Men } & \multicolumn{4}{|c|}{ Women } & \multirow[b]{2}{*}{$P \dagger$} \\
\hline & $n$ & Mean* & $P_{20}$ & $P_{80}$ & $n$ & Mean* & $P_{20}$ & $P_{80}$ & \\
\hline \multicolumn{10}{|l|}{ Intake $\left(\mathrm{g} \mathrm{day}^{-1}\right)$} \\
\hline Total & 116 & 323 & 207 & 477 & 153 & 351 & 240 & 484 & NS \\
\hline Fruit & 116 & 160 & 63 & 297 & 153 & 216 & 122 & 322 & $<0.01$ \\
\hline Vegetables & 116 & 160 & 91 & 214 & 153 & 141 & 95 & 192 & $<0.05$ \\
\hline \multicolumn{10}{|c|}{ Frequency (servings day ${ }^{-1}$ ) } \\
\hline Total & 116 & 3.7 & 2.4 & 5.5 & 153 & 4.2 & 2.7 & 5.9 & $<0.05$ \\
\hline Fruit & 116 & 1.4 & 0.6 & 2.6 & 153 & 2.0 & 1.1 & 2.9 & $<0.001$ \\
\hline Vegetables & 116 & 2.2 & 1.5 & 3.1 & 153 & 2.3 & 1.3 & 3.3 & NS \\
\hline \multicolumn{10}{|l|}{ Serving size (g) } \\
\hline Total & 116 & 89 & 73 & 107 & 153 & 84 & 69 & 107 & NS \\
\hline Fruit & 110 & 116 & 97 & 141 & 151 & 112 & 90 & 135 & NS \\
\hline Vegetables & 116 & 71 & 54 & 95 & 152 & 63 & 49 & 79 & 0.001 \\
\hline
\end{tabular}

$\mathrm{P}_{20}$ - 20th percentile; $\mathrm{P}_{80}-$ 80th percentile; $\mathrm{NS}$ - not significant.

* Figures are geometric means (unadjusted).

$\dagger$ By linear regression adjusting for age.

vegetables ( $58.4 \%$ fruit) whereas men consumed a slightly greater proportion of vegetables than of fruit ( $48.5 \%$ fruit).

\section{Serving sizes of individual foods}

Fruit and vegetable serving sizes were generally skewed (Tables 2 and 3). The largest serving weights were observed for commonly eaten fruits such as oranges, apples and bananas. Soft fruits such as peaches, strawberries and raspberries were also eaten in relatively large servings $(>80 \mathrm{~g})$. As expected, dried fruits were consumed in smaller servings $(<30 \mathrm{~g})$. Average serving sizes of frequently consumed vegetables such as carrots, peas, broccoli and cauliflower were also less than $80 \mathrm{~g}$, but servings of canned beans were considerably above $80 \mathrm{~g}$.

Table 2 Average serving sizes of vegetables $(\mathrm{g})$

\begin{tabular}{lrrrrrr}
\hline Food & $n$ & Mean & SEM & Median & $\mathrm{P}_{20}$ & $\mathrm{P}_{80}$ \\
\hline Broccoli & 180 & 72 & 3 & 54 & 54 & 89 \\
Brussels sprouts & 96 & 63 & 3 & 56 & 39 & 87 \\
Cabbage & 171 & 84 & 3 & 90 & 58 & 96 \\
Carrots & 432 & 56 & 1 & 61 & 39 & 72 \\
Cauliflower & 165 & 81 & 3 & 60 & 60 & 114 \\
Courgette & 34 & 65 & 7 & 60 & 33 & 94 \\
Cucumber & 262 & 34 & 2 & 24 & 20 & 40 \\
Leeks & 27 & 84 & 12 & 67 & 45 & 104 \\
Lettuce & 368 & 26 & 1 & 24 & 15 & 33 \\
Mushroom & 101 & 50 & 4 & 40 & 21 & 66 \\
Onion & 131 & 53 & 4 & 46 & 17 & 71 \\
Parsnips & 73 & 52 & 4 & 42 & 33 & 65 \\
Peas & 301 & 56 & 2 & 45 & 29 & 81 \\
Pepper & 43 & 32 & 4 & 20 & 10 & 60 \\
Spinach & 19 & 107 & 5 & 97 & 97 & 136 \\
Swede & 47 & 55 & 5 & 47 & 35 & 67 \\
Sweet corn & 43 & 101 & 24 & 43 & 28 & 105 \\
Tomato & 691 & 86 & 2 & 85 & 43 & 120 \\
Soups & 157 & 65 & 3 & 48 & 36 & 102 \\
Dried beans & 209 & 72 & 2 & 60 & 55 & 90 \\
Canned beans & 148 & 147 & 7 & 137 & 79 & 210 \\
Mixed salad & 167 & 74 & 2 & 75 & 45 & 90 \\
Vegetable dishes & 122 & 99 & 7 & 75 & 24 & 174 \\
Tela & & & & & &
\end{tabular}

SEM - standard error of the mean; $P_{20}-20$ th percentile; $P_{80}-80$ th percentile.

\section{Average serving sizes per person}

The geometric mean weight of a serving of fruit and vegetables combined per person was $86.2 \mathrm{~g}$ (95\% CI 83.6$89.0 \mathrm{~g})$. Average serving sizes for fruits and vegetables grouped by sex are presented in Table 1 . Overall, men ate slightly larger servings of fruit and vegetables than did women, but age-adjusted differences were small and were significant only for serving sizes of vegetables $(P=0.001)$.

\section{Frequency of fruit and vegetable intakes}

Women ate fruits more often than men (women vs. men: 2.0 vs. 1.4 portions day ${ }^{-1}, P<0.001$ ), but there were no sex differences in the number of servings of vegetables consumed daily. Overall, women consumed combined fruit and vegetables more frequently than did men (women vs. men: 4.2 vs. 3.7 portions day $^{-1}, P<0.05$ ).

Table 3 Average serving sizes of fruits (g)

\begin{tabular}{lrrrrrr}
\hline Food & $n$ & Mean & SEM & Median & $P_{20}$ & $P_{80}$ \\
\hline Apple & 803 & 113 & 1 & 112 & 112 & 112 \\
Banana & 575 & 95 & 1 & 100 & 80 & 100 \\
Blackberry & 16 & 101 & 17 & 76 & 70 & 140 \\
Blackcurrant & 11 & 39 & 8 & 40 & 10 & 57 \\
Dried fruits & 129 & 31 & 2 & 28 & 16 & 40 \\
Fruit salad & 75 & 128 & 6 & 130 & 81 & 184 \\
Grapefruit & 165 & 126 & 3 & 116 & 116 & 140 \\
Grapes & 125 & 83 & 4 & 70 & 50 & 114 \\
Kiwi & 30 & 52 & 3 & 60 & 30 & 65 \\
Melon & 56 & 168 & 11 & 151 & 102 & 227 \\
Orange & 176 & 163 & 3 & 160 & 120 & 210 \\
Orange varieties & 121 & 74 & 2 & 70 & 60 & 96 \\
(e.g. satsuma) & & & & & & \\
Peaches & 78 & 97 & 5 & 120 & 52 & 122 \\
Pears & 151 & 158 & 4 & 160 & 127 & 170 \\
Pineapple & 45 & 81 & 7 & 80 & 41 & 112 \\
Plums/greengages & 81 & 112 & 8 & 92 & 46 & 159 \\
Prunes & 67 & 31 & 2 & 24 & 20 & 49 \\
Raspberries & 37 & 107 & 12 & 114 & 36 & 219 \\
Rhubarb & 21 & 106 & 15 & 90 & 55 & 140 \\
Strawberries & 83 & 103 & 6 & 96 & 60 & 150 \\
Plaw & & & & & &
\end{tabular}

SEM - standard error of the mean; $P_{20}-20$ th percentile; $P_{80}-80$ th percentile. 


\section{Characteristics of high and low fruit and vegetable} consumers

When subjects were grouped into low $\left(<400 \mathrm{~g} \mathrm{day}^{-1}\right)$ and high $\left(\geq 400 \mathrm{~g} \mathrm{day}^{-1}\right.$ ) consumers, $63.2 \%$ were categorised as low consumers. Forty-two per cent of women were high consumers, but only $29 \%$ of men fell into this category. Table 4 shows that frequency of intake had much more impact on classification than serving size. After adjusting for age and sex differences, high consumers ate 5.7 (95\% CI 5.4-6.1) portions of combined fruit and vegetables per day whereas low consumers ate $3.2(95 \% \mathrm{CI}$ 3.0-3.4) portions per day $(P<0.001)$. Low consumers also ate slightly smaller servings than the high consumers (differences for combined fruit and vegetables $\sim 11 \mathrm{~g}$, $P<0.001 ;$ fruit $\sim 8 \mathrm{~g}, \quad P=0.053 ;$ vegetables $\sim 4 \mathrm{~g}$, $P=0.17)$.

\section{Discussion}

In this group of British adults selected from the EPICNorfolk study, more than $60 \%$ of subjects had fruit and vegetable intakes below the recommended level of $400 \mathrm{~g} \mathrm{day}^{-1}$. By comparing high and low consumers we have identified that intake is determined by frequency, rather than portion size. The $80 \mathrm{~g}$ reference portion size for fruits and vegetables is appropriate, on average, but there is wide variation. For example, within the median intake of $61 \mathrm{~g}$ of carrots, $20 \%$ eat less than $39 \mathrm{~g}$ and $20 \%$ eat more than $72 \mathrm{~g}$ per portion; similarly for strawberries the median intake was $103 \mathrm{~g}$ with $20 \%$ eating less than $60 \mathrm{~g}$ and 20\% eating more than $150 \mathrm{~g}$.

Generally, average serving sizes were below $80 \mathrm{~g}$ for commonly consumed vegetables and above $80 \mathrm{~g}$ for fruits. This has been reported previously, but differences between serving sizes of these two food groups were much smaller than observed here and portion sizes were generally closer to $80 \mathrm{~g}^{8}$. There was greater agreement between the portion sizes observed in the current study and those reported in the National Diet and Nutrition

Table 4 Age- and sex-adjusted fruit and vegetable intakes of low and high consumers

\begin{tabular}{|c|c|c|c|c|}
\hline & $n$ & Low $^{\star}$ & $n$ & High* $^{*}$ \\
\hline \multicolumn{5}{|c|}{ Intake $\left(\right.$ g day $\left.^{-1}\right)$} \\
\hline Total & 170 & $260(248-273)$ & 99 & $531(498-566) \dagger$ \\
\hline Fruit & 170 & $128(115-142)$ & 99 & $329(300-358) \dagger$ \\
\hline Vegetables & 170 & $124(115-134)$ & 99 & $197(182-212) \dagger$ \\
\hline \multicolumn{5}{|c|}{ Frequency (servings day ${ }^{-1}$ ) } \\
\hline Total & 170 & $3.2(3.0-3.4)$ & 99 & $5.7(5.4-6.1) \dagger$ \\
\hline Fruit & 170 & $1.2(1.1-1.3)$ & 99 & $2.8(2.6-3.1) \dagger$ \\
\hline Vegetables & 170 & $1.9(1.8-2.1)$ & 99 & $2.9(2.6-3.1) \dagger$ \\
\hline \multicolumn{5}{|c|}{ Serving size $(\mathrm{g})$} \\
\hline Total & 170 & $82(79-86)$ & 99 & $93(89-98) \dagger$ \\
\hline Fruit & 162 & $111(106-116)$ & 99 & $119(112-125)$ \\
\hline Vegetables & 169 & $65(62-68)$ & 99 & $69(65-73)$ \\
\hline
\end{tabular}

${ }^{*}$ Figures are geometric mean (95\% confidence interval).

† Significantly different from low fruit and vegetable consumers after adjusting for age and sex differences, $P<0.001$.
Survey, but the serving sizes of only a few foods were presented in that report?

Over the past five years a gradual increase in total fruit intakes and a reduction in total vegetable intakes have been observed ${ }^{1}$. The increase in total fruit intakes is due partly to increased consumption of fruit juice. It is generally agreed that, for the maximum benefit to be achieved from fruit, only one portion of fruit juice should contribute to current '5-a-day' targets, the rest coming from whole foods. The data presented here include all instances of fruit juice consumption reported in the food diaries regardless of frequency or amount. Reanalysis of our data (excluding fruit juice) showed that fruit juice contributed $\sim 40 \mathrm{~g} \mathrm{day}^{-1}$ to total fruit and vegetable intakes (data not shown).

Men and women ate similar total amounts of fruits and vegetables, but the relative contribution of fruits and vegetables was different in men and women. These different patterns of consumption suggest that advice to increase fruit and vegetable intakes may need to be gender-specific.

Comparison of fruit and vegetable consumption patterns between high and low consumers indicated that differences in intake frequency were more important than differences in portion sizes. Low consumers ate total fruit, total vegetables and combined fruit and vegetables significantly less often than did high consumers, but there were only small differences in portion size between these two groups. The $37 \%$ of this cohort who had average intakes above $400 \mathrm{~g} \mathrm{day}^{-1}$ achieved the 5-a-day target whilst low consumers achieved only 3-a-day.

Fruit and vegetable serving sizes were complementary, producing average combined fruit and vegetable serving sizes of at least $80 \mathrm{~g}$, even in low consumers. This means that the current reference portion size $(80 \mathrm{~g})$ is a fair estimation and justifies the '5-a-day' target. Strategies to increase average fruit and vegetable intakes towards $400 \mathrm{~g}$ should therefore focus on encouraging consumers to eat fruits and vegetables more often.

\section{Acknowledgements}

This study was supported by the '5-a-day' Programme, Department of Health, London. We acknowledge the work of the EPIC-Norfolk study team who collected and processed the data presented in this report.

\section{References}

1 Great Britain National Food Survey Committee. National Food Survey: 2000. Department of Environment, Food and Rural Affairs. London: The Stationery Office, 2001.

2 Agudo A, Amiano P, Barcos A, Barricarte A, Beguiristain JM, Chirlaque MD, et al. Dietary intake of vegetables and fruits among adults in five regions of Spain. EPIC Group of Spain. European Journal of Clinical Nutrition 1999; 53: 174-80.

3 Naska A, Vasdekis VG, Trichopoulou A, Friel S, Leonhauser 
IU, Moreiras O, et al. Fruit and vegetable availability among ten European countries: how does it compare with the 'five-aday' recommendation? DAFNE I and II projects of the European Commission. British Journal of Nutrition 2000; 84: 549-56.

4 World Health Organization (WHO). Diet, Nutrition and The Prevention of Chronic Diseases. Technical Report Series No. 797. Geneva: WHO, 1990.

5 Bingham SA, Welch AA, McTaggart A, Mulligan AA, Runswick $\mathrm{SA}$, Luben R, et al. Nutritional methods in the European Prospective Investigation of Cancer in Norfolk. Public Health Nutrition 2001; 4(3): 847-58.
6 Welch AA, McTaggart A, Mulligan AA, Luben R, Walker N, Khaw KT, et al. DINER (Data Into Nutrients for Epidemiological Research) - a new data-entry program for nutritional analysis in the EPIC-Norfolk cohort and the 7-day diary method. Public Health Nutrition 2001; 4(6): 1253-65.

7 Crawley H. Food Portion Sizes, 2nd ed. Ministry of Agriculture, Fisheries and Food. London: HMSO, 1993.

8 Williams C. Healthy eating: clarifying advice about fruit and vegetables. British Medical Journal 1995; 310: 1453-5.

9 Ministry of Agriculture, Fisheries and Food. The Dietary and Nutritional Survey of British Adults - Further Analysis. London: HMSO, 1994. 